\title{
Research on the escape mechanism and influencing factors of harmful gas induced by blasting excavation in deep rock tunnel
}

Yi Luo

Wuhan University of Technology

Hangli Gong ( $\nabla$ hangligong58@whut.edu.cn )

Wuhan University of Technology

Dengxing Qu

Wuhan University of Technology

Xinping Li

Wuhan University of Technology

Shaohua Hu

Wuhan University of Technology

Yingwei Zhu

Wuhan University of Technology

Qingsong Pu

Wuhan University of Technology

\section{Research Article}

Keywords: Tunnel blasting excavation, Multi-field coupling effect, Toxic and harmful gas, Escape mechanism, Surrounding rock damage

Posted Date: November 12th, 2021

DOI: https://doi.org/10.21203/rs.3.rs-1068339/v1

License: (a) (1) This work is licensed under a Creative Commons Attribution 4.0 International License. Read Full License 
Research on the escape mechanism and influencing factors of harmful gas induced by blasting excavation in deep rock tunnel

\section{Yi Luo ${ }^{1,4}$, Hangli Gong ${ }^{2,4}$, Dengxing $\mathrm{Qu}^{3, *}$, Xinping Li ${ }^{1,4}$, Shaohua $\mathrm{Hu}^{3}$, Yingwei $\mathrm{Zhu}^{2}$, Qingsong $\mathrm{Pu}^{2}$}

${ }^{1}$ Hubei Key Laboratory of Roadway Bridge and Structure Engineering, Wuhan University of Technology, Wuhan 430070, China

${ }^{2}$ School of Civil Engineering and Architecture, Wuhan University of Technology, Wuhan 430070, China

${ }^{3}$ School of Safety Science and Emergency Management, Wuhan University of Technology, Wuhan 430070, China

${ }^{4}$ Sanya Science and Education Innovation Park, Wuhan University of Technology, Sanya 572024, China

* Corresponding author. Dengxing Qu, School of Safety Science and Emergency Management, Wuhan 430070,China.E-mail address: dengxingqu@whut.edu.cn

Abstract: The escape of toxic and harmful gases is a common disaster effect in tunnel engineering. Frequent drilling and blasting excavation disturbances under high in-situ stress environment will inevitably lead to cumulative damage effect on surrounding rock, which will increase the risk of toxic and harmful gas escape, and seriously endanger construction safety. In this paper, based on real-time monitoring data of harmful gases during blasting and excavation of Yuelongmen Tunnel on Chengdu-Lanzhou Railway, this study summarized laws and distribution characteristics of harmful gas escape intensified by the blasting excavation, and the effectiveness of shotcreting and grouting for water blocking to inhibit gas escape is verified. Then, taking water-containing and gas-containing voids as carriers, considering the influence of different in-situ stress, explosion load and void parameters (including void pressure, void diameter and distance between void and tunnel), to carry out research on the escape mechanism of water-soluble $\left(\mathrm{H}_{2} \mathrm{~S}\right)$ and insoluble $\left(\mathrm{CH}_{4}\right)$ toxic and harmful gases under the coupling effect of stress-seepage-damage. The relationship between the amount of harmful gas escaped and the damage degree of the surrounding rock of the tunnel is analyzed, and the functional relationship between it and the in-situ stress, explosion load and cave parameters is established. The results further demonstrate that the amount of escaped harmful gases, such as methane and $\mathrm{H}_{2} \mathrm{~S}$ is closely related to lithology of surrounding rock, occurrence conditions of the deep rock mass, development degree of structural fractures and void parameters. The damage of surrounding rock caused by dynamic disturbance during blasting excavation is the main reason of aggravating harmful gas escape. The research results can provide a theoretical reference for preventing harmful gas from escaping in the similar engineering construction.

Keywords: Tunnel blasting excavation; Multi-field coupling effect; Toxic and harmful gas; 
Escape mechanism; Surrounding rock damage

\section{Introduction}

With the continuous laying of the railway network in China to the southwest, tunnels have become key projects in the railway network in the southwest region due to restrictions of geographical conditions, such as mountains and hills in the region. Drilling and blasting method is the main method for the construction of tunnels in deep rock mass because of its simple construction process, high efficiency and economic efficiency (Hong et al., 2017; Zhang et al., 2020b; Huang et al., 2019). However, while breaking rock mass, this method produces strong dynamic disturbance to retaining rock mass, so that joints and fractures in surrounding rock propagate and coalesce, which aggravates damages to, and raises permeability coefficient of, surrounding rock. In addition, the influences that cumulative damage effects of dynamic disturbance caused by frequent blasting excavation on surrounding rock of tunnels accelerate harmful gas escape also cannot be ignored. After blasting for many times, a lot of toxic and harmful gases, such as methane and $\mathrm{H}_{2} \mathrm{~S}$ are often contained in the air of tunnels, and they are likely to accumulate in the unsupported parts, causing major safety accidents and harming operators and environment to different degrees (Abdollahisharif et al., 2016; Paoin et al., 2020; Marcia et al., 2007; Yan et al., 2020a). In tunnel construction, it is particularly important to prevent outburst of harmful gases, like methane and $\mathrm{H}_{2} \mathrm{~S}$, and a lot of related accidents have been reported all over the world (Gao et al., 2020; Wang et al., 2018a; Zhang et al., 2018c). Therefore, from the perspectives of ensuring safety of construction personnel and protecting the environment, ensuring air quality in cavities has become a prerequisite for environmental-friendly and safe tunnel construction.

In recent years, researchers at home and abroad mainly focus on the occurrence and migration mechanism of toxic and harmful gases in deep rock mass. Among them, Creedy et al. (1988) and Pan et al. (2014) have shown that the occurrence and migration mechanism of gas and other harmful gases is significantly related to the geological structure; Naveen et al. (2018) found that the heterogeneity of the pore surface and the irregularity of the pore matrix in the gas reservoir have a greater impact on the gas adsorption capacity and migration. Shepherd et al. (1981) confirmed that mining disturbance during tunnel construction will further aggravate the escape of harmful gases. Therefore, the diffusion law of harmful gases after blasting in deep tunnel engineering has also become the focus of research (Chang et al.,2020; Kurnia et al., 2015; Cong et al., 2021). Numerous studies have shown that measures such as optimization of ventilation duct arrangement (Yan et al. 2020; Luginet al. 2019; Yanget al. 2020), nitrate or alkali dilution (Olga et al. 2015) and air-tight concrete plugging (Wang et al. 2013; Kang et al. 2008) can effectively reduce the concentration of harmful gas in the tunnel and prevent its accumulation. Similarly, some scholars have also carried out research on advanced prevention methods of harmful gas, and proposed that pre-splitting blasting control (Xue et al. 2017) and drilling pre-discharge (Xu et al. 2017; Lin et al. 2015; Zhang et al. 2013) can effectively reduce the risk of 
harmful gas emissions during the construction process. In addition, since deep rock tunnels are significantly affected by high in-situ stress, high osmotic pressure, high temperature, etc., when studying the impact of blasting excavation on surrounding rock damage, the coupling effect of stress field and seepage field is more obvious (Zhu et al. 2019). EIsworth et al. (1986) studied the relationship between the permeability and strain of rock specimens during the deformation process in 1986, and proposed introducing damage to study the permeability problem. Based on numerical simulation and experimental research, Shao et al. (2000)and Tang et al. (2002) verified that the progressive process of material deterioration and fracture can be quantitatively analyzed by considering multi-field coupling effects such as damage and seepage. However, there are few studies on the escape mechanism of harmful gases under the coupling action of stress field, damage field and seepage field, and the damage characteristics of surrounding rock under the coupling action of multiple fields need to be further studied.

By combining with real-time monitoring data in the field of actual projects, this research summarized escape laws and distribution characteristics of harmful gas aggravated by blasting excavation. By taking water-containing voids and gas-containing voids as carriers, this study discussed influence laws of factors, such as blasting load, properties of surrounding rock and parameters of the water-containing void and gas-containing void on harmful gas escape through numerical simulation. Furthermore, the comprehensive analysis revealed mechanisms of harmful gas escape aggravated by blasting excavation of a tunnel in deep rock mass. The research results can provide a theoretical reference for preventing harmful gas from escaping in the similar engineering construction.

\section{Engineering background}

\section{Engineering characteristics of Yuelongmen Tunnel}

Yuelongmen Tunnel on Chengdu-Lanzhou Railway, located in the famous Longmenshan tectonic belt, passes through Longmen Mountains and has high construction risks. Double tracks are separately constructed along the whole line. The total lengths of the left and right tracks are 19,981 $\mathrm{m}$ and 20,042 $\mathrm{m}$ and the parallel adit is 9,679.033 $\mathrm{m}$ in length. The whole section is generally buried deeply and the maximum buried depth is about $1,450 \mathrm{~m}$. The section with buried depth larger than $500 \mathrm{~m}$ accounts for $77.34 \%$ of the total length of the whole line, and that with the buried depth larger than $800 \mathrm{~m}$ occupies $13.17 \%$. Surrounding rock of the whole tunnel line is dominated by carbonaceous rock and surrounding rock in grades V and IV accounts for $91 \%$ in the total length of the tunnel. Affected by the Wenchuan earthquake on May 12, 2008, the surrounding rock of the whole line had been softened. The scheme with three transverse galleries, two inclined shafts and one parallel adit was adopted in the auxiliary tunnel, as shown in Fig. 1. 
112

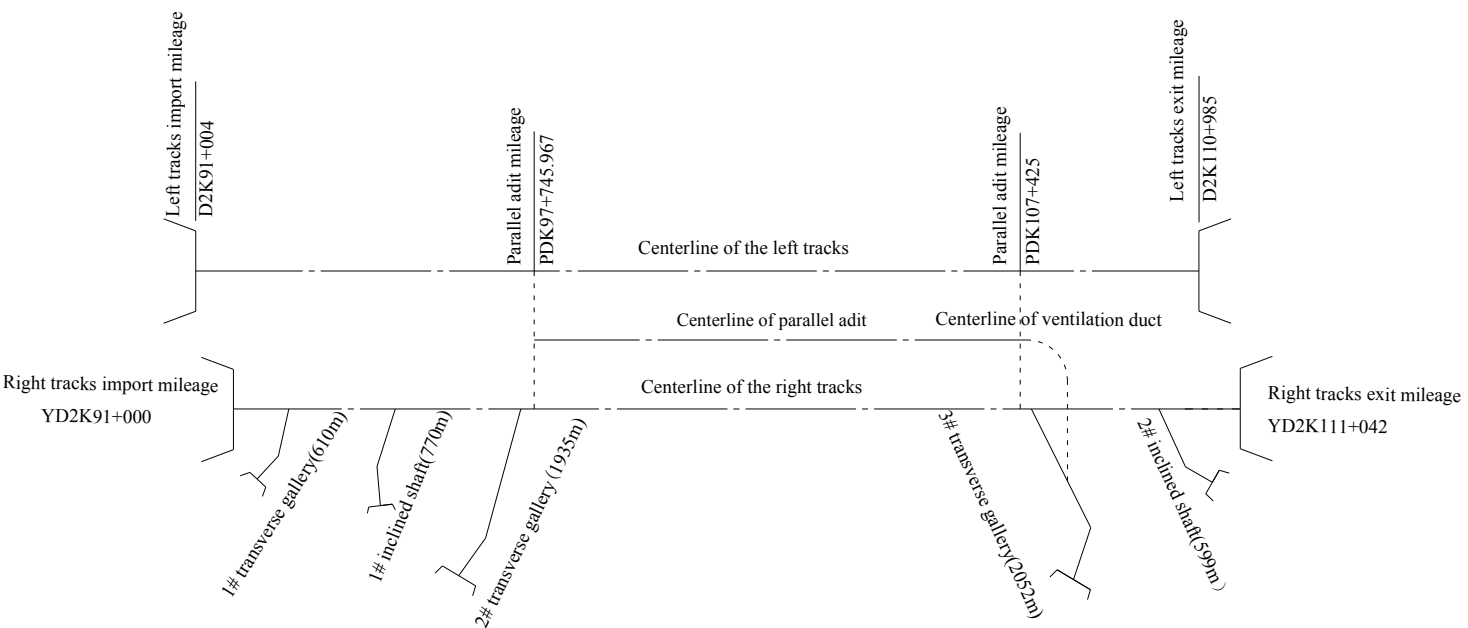

Fig. 1. Construction section of Yuelongmen Tunnel.

The working area of the tunnel is rich in groundwater, mainly composed of pore phreatic water in soil layers, fracture water in bedrock and water in fault zones, so water gushing and mud bursting accidents tend to occur. The carbonaceous rock of the whole tunnel is of thin-plate structures with developed joints and fractures. During the construction, harmful gases, such as $\mathrm{H}_{2} \mathrm{~S}$ and high-content methane escaped successively, resulting in superposition of multiple extremely high safety risks. To clarify escape laws and distribution characteristics of harmful gases including $\mathrm{H}_{2} \mathrm{~S}$ and methane during blasting excavation, the concentration of harmful gas in the working area of the tunnel was monitored in real time. This was based on layout principle of the automatic monitoring system for harmful gas shown in Fig. 2. In addition, Fig. 3 demonstrates blasting excavation of the working area of the tunnel and actual situations of a tunnel face.

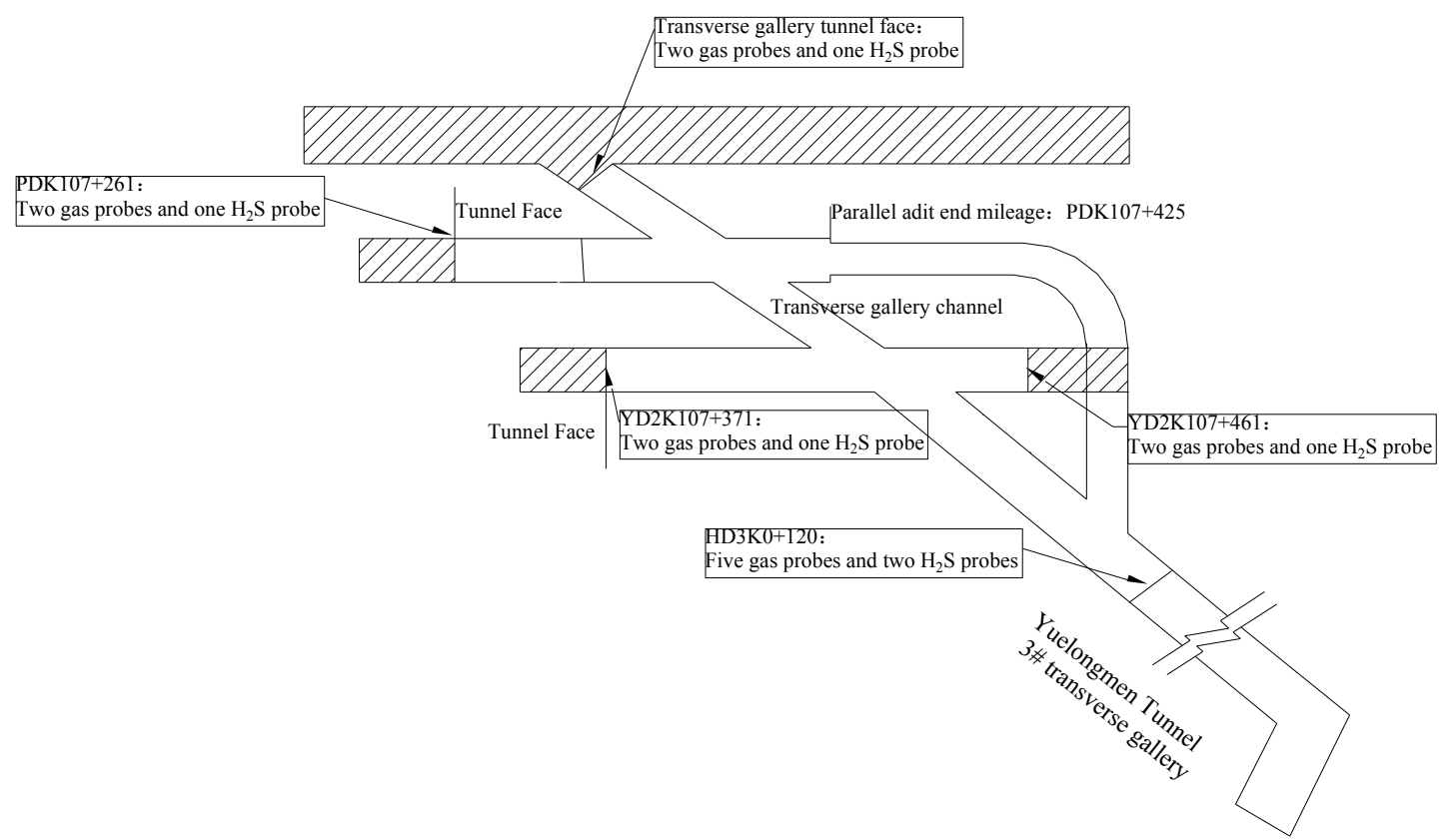

(a) 3\# transverse gallery monitoring system. 


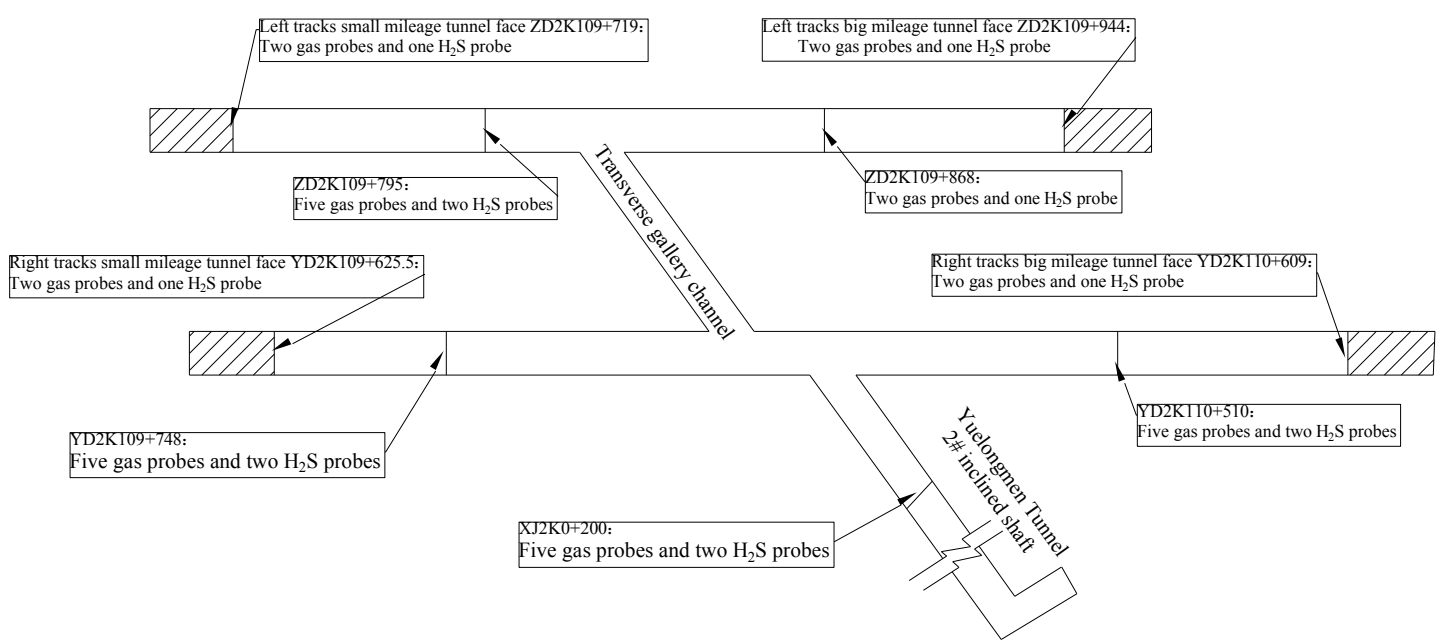

127 128

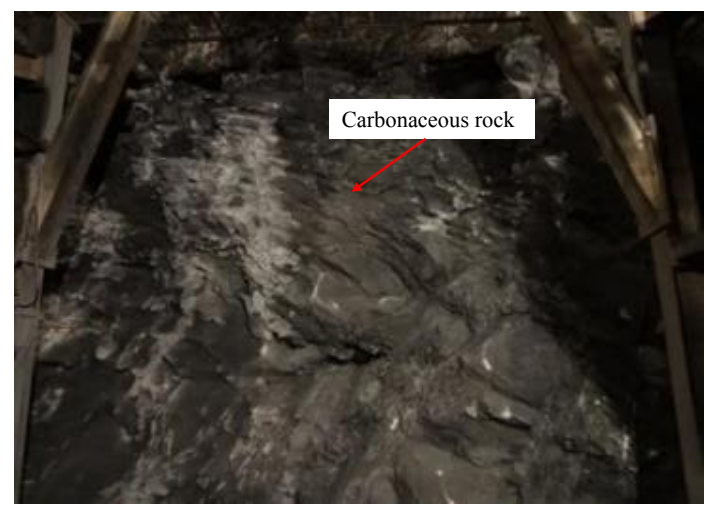

(b) 2\# inclined shaft monitoring system.

Fig. 2. Automatic monitoring system for harmful gas in tunnel working area.

Fig. 3. Tunnel face of HD3K0+148 section.

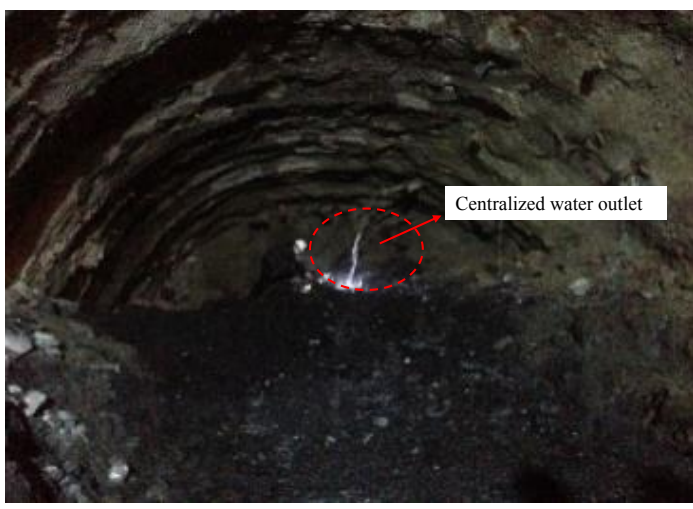

\section{Gas escape and distribution characteristics}

Monitoring data of gas concentration obtained from 3\# transverse gallery at HD3K0+120 and $2 \#$ inclined shaft at $\mathrm{XJ} 2 \mathrm{~K} 0+080$ were analyzed and time-history curves thereof were drawn, as shown in Figs. 4. Geological reports point out that surrounding rock of the 3\# transverse gallery is dominated by carbonaceous slates, while carbonaceous phyllite is mainly found in the $2 \#$ inclined shaft. Monitoring data illustrate that detected gas concentration is found exceeding standard or tends to increase after excavation at the tunnel face and the return airway. Because gas escape is closely related to distribution of carbonaceous slates and development degree of structural factures, gas concentration would increase suddenly and be distributed extremely non-uniformly when a gas-containing void in structural fractures was opened by explosives. In the meanwhile, the time-history curves of gas concentration at each mileage for monitoring show characteristics, such as wave crest, slope and platform, further indicating that gas emission has a close correlation with geological conditions of surrounding rock and excavation process. 


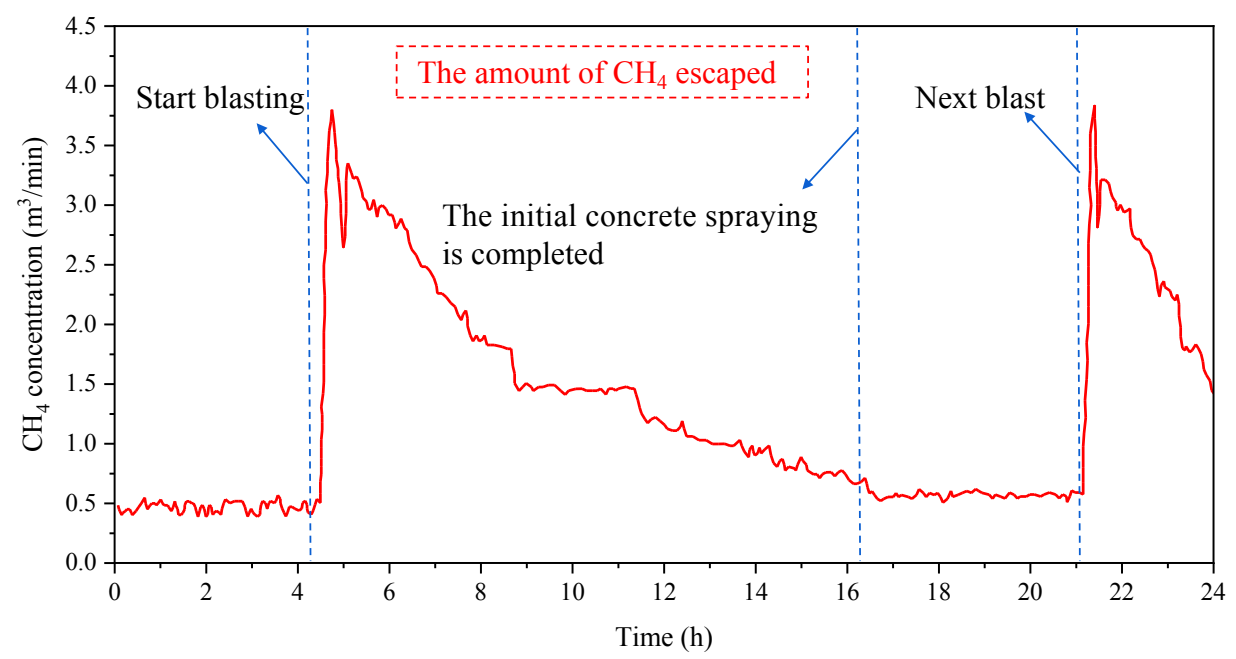

(a) 3\# transverse gallery HD3K0+120 mileage.

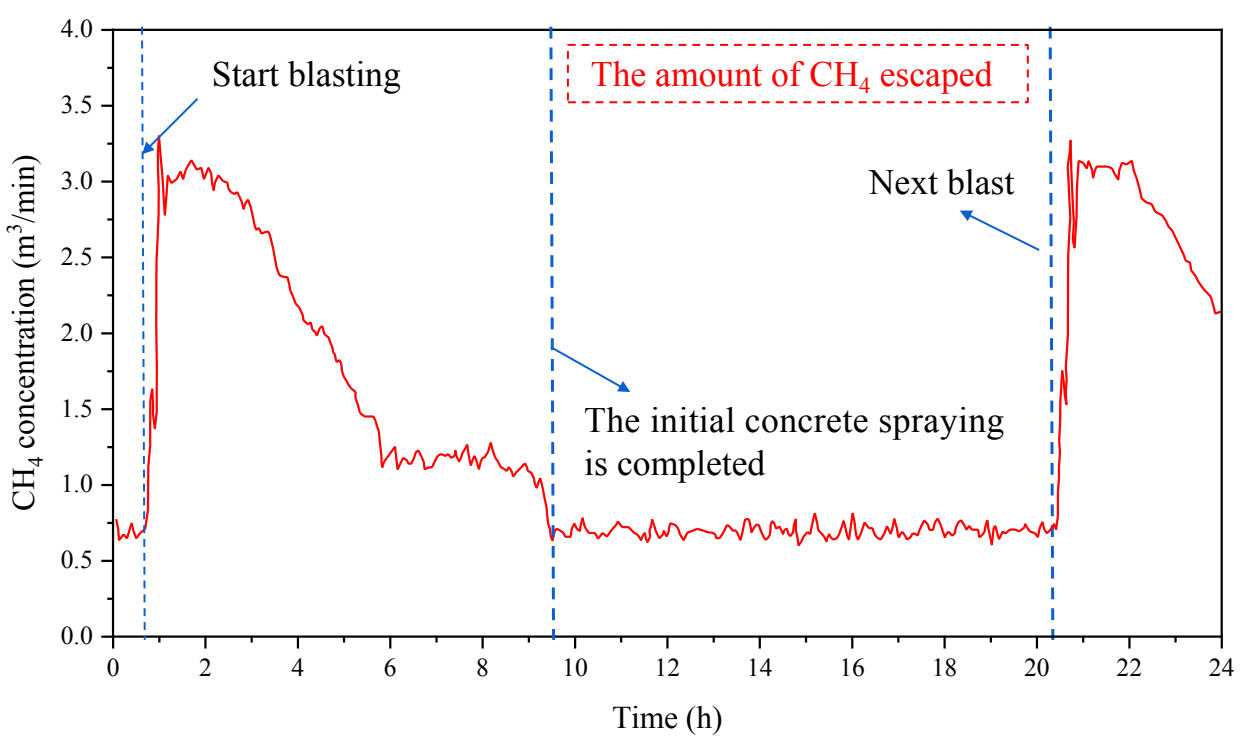

(b) 2\# inclined shaft XJ2K0+200 mileage.

Fig. 4. Time-history curve of gas concentration.

Data in Fig. 4(a) show that the maximum and minimum gas emissions separately are 3.84 and $0.42 \mathrm{~m}^{3} / \mathrm{min}$, with an average of about $1.65 \mathrm{~m}^{3} / \mathrm{min}$ and the duration during which the concentration exceeds $1 \mathrm{~m}^{3} / \mathrm{min}$ in a single day is longer than $12 \mathrm{~h}$. Data in Fig. 4(b) illustrate that the maximum and minimum gas emissions separately reach 3.28 and 0.52 $\mathrm{m}^{3} / \mathrm{min}$, with an average of about $1.42 \mathrm{~m}^{3} / \mathrm{min}$. The duration during which the concentration exceeds $1 \mathrm{~m}^{3} / \mathrm{min}$ in a single day is longer than $10 \mathrm{~h}$. This suggests that blasting excavation significantly affects the amount of gas escaped, mainly evinced by the gas concentration rising significantly after blasting, and the concentration increases by as much as $300 \sim 400 \%$ after a single blasting and reaches the peak after 10 30 min, lasting for about 65 195 min. The gas concentration decreases for a long time, and that on some platforms is around 1.5 $\mathrm{m}^{3} / \mathrm{min}$. It is speculated that gas emits in the process of mucking, and the amount of methane overflowing from the tunnel face and released by slag blocks decreases with the amount of 
residual slag in the process of mucking and then reduces to the lowest after shotcreting as primary supports.

\section{Escape and distribution characteristics of water-soluble $\mathrm{H}_{2} \mathrm{~S}$}

$\mathrm{H}_{2} \mathrm{~S}$ concentrations in the working areas of the $3 \#$ transverse gallery and $2 \#$ inclined shaft were monitored in real time. Fig. 5(a) shows the $\mathrm{H}_{2} \mathrm{~S}$ concentration in a single day at different mileages of the $3 \#$ transverse gallery, which is generally $1 \sim 6 \mathrm{ppm}$. The $\mathrm{H}_{2} \mathrm{~S}$ concentration from HD3K0+140 to HD3K0+260 is obviously high, where the humidity in the tunnel is about $70 \sim 76 \%$. Field inspection shows that there is a centralized water outlet at HD3K0+148, with water discharge of about $615 \mathrm{~m}^{3} / \mathrm{h}$, as displayed in Fig. 6. Fig. 5(b) demonstrates that the $\mathrm{H}_{2} \mathrm{~S}$ concentration in a single day at different mileages of the 2\# inclined shaft is generally $1 \sim 8 \mathrm{ppm}$. Although there is no obvious water outlet from $\mathrm{XJ} 2 \mathrm{~K} 0+50$ to $\mathrm{XJ} 2 \mathrm{~K} 0+250$, the humidity in this interval is about $51 \sim 64 \%$ and the $\mathrm{H}_{2} \mathrm{~S}$ concentration is obviously higher than those at the other mileages.

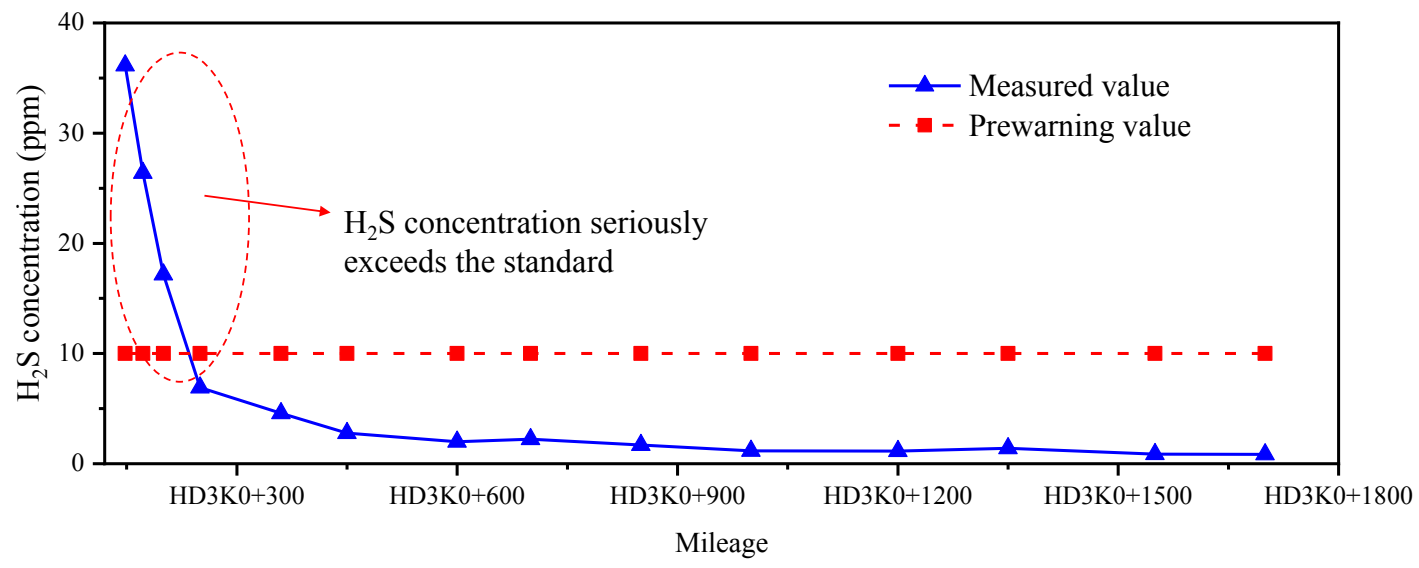

(a) $3 \#$ transverse gallery.

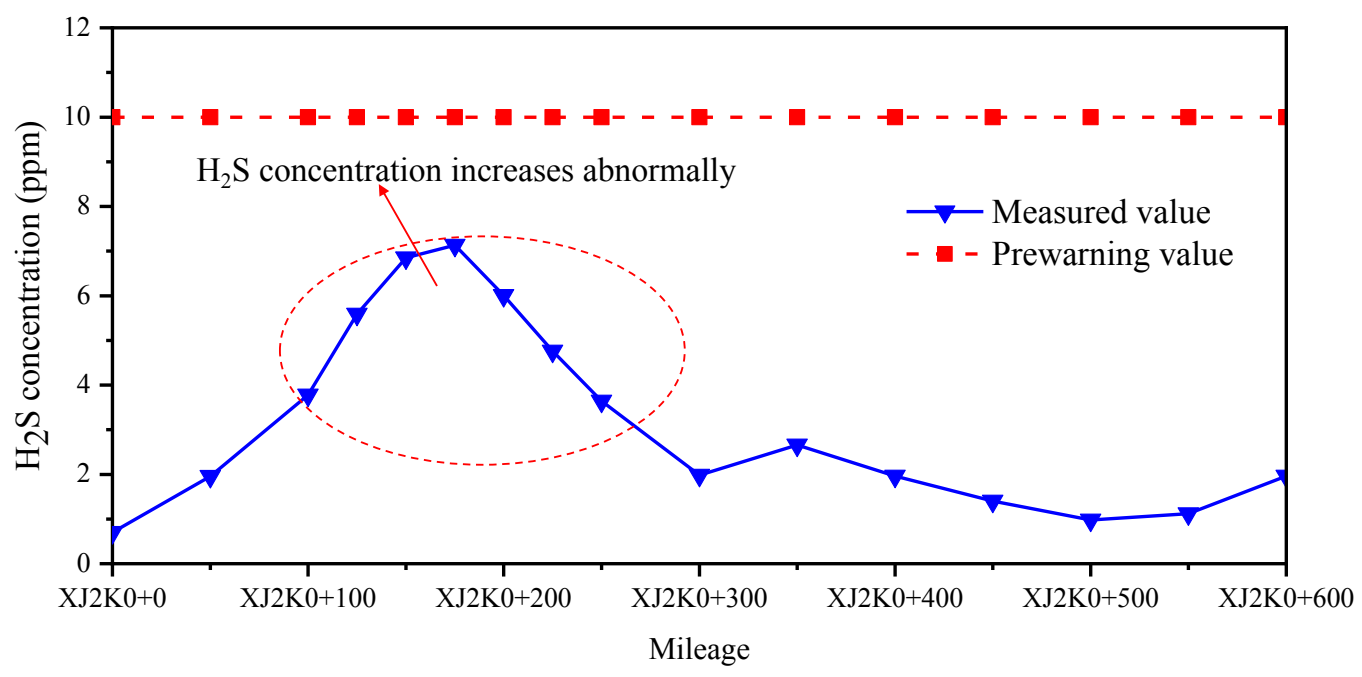

(b) $2 \#$ inclined shaft.

Fig. 5. $\mathrm{H}_{2} \mathrm{~S}$ concentration monitoring value in a single day. 
To further study changes of $\mathrm{H}_{2} \mathrm{~S}$ concentration around the centralized water outlet at HD3K0+148 of the $3 \#$ transverse gallery, field measurement illustrates that the $\mathrm{H}_{2} \mathrm{~S}$ concentration at the water outlet is up to $91.4 \mathrm{ppm}$. A group of data was read every $10 \mathrm{~cm}$ around and in front of the water outlet, as shown in Fig. 6. The data in the figure demonstrate that the $\mathrm{H}_{2} \mathrm{~S}$ concentration extremely obviously reduces with the increasing distance from the water outlet. To be specific, at $10 \mathrm{~cm}$ away from the water outlet, $\mathrm{H}_{2} \mathrm{~S}$ concentration in front and below the outlet reaches about $28 \mathrm{ppm}$, it decreases to $13 \mathrm{ppm}$ at location $30 \mathrm{~cm}$ from the water outlet and $7.3 \mathrm{ppm}$ at position $50 \mathrm{~cm}$ from the water outlet. This indicates that $\mathrm{H}_{2} \mathrm{~S}$ is controlled by geological structures and associated with groundwater, namely a positive correlation with groundwater. Excavation disturbance further aggravates the escape of $\mathrm{H}_{2} \mathrm{~S}$ from carbonaceous phyllite and groundwater.
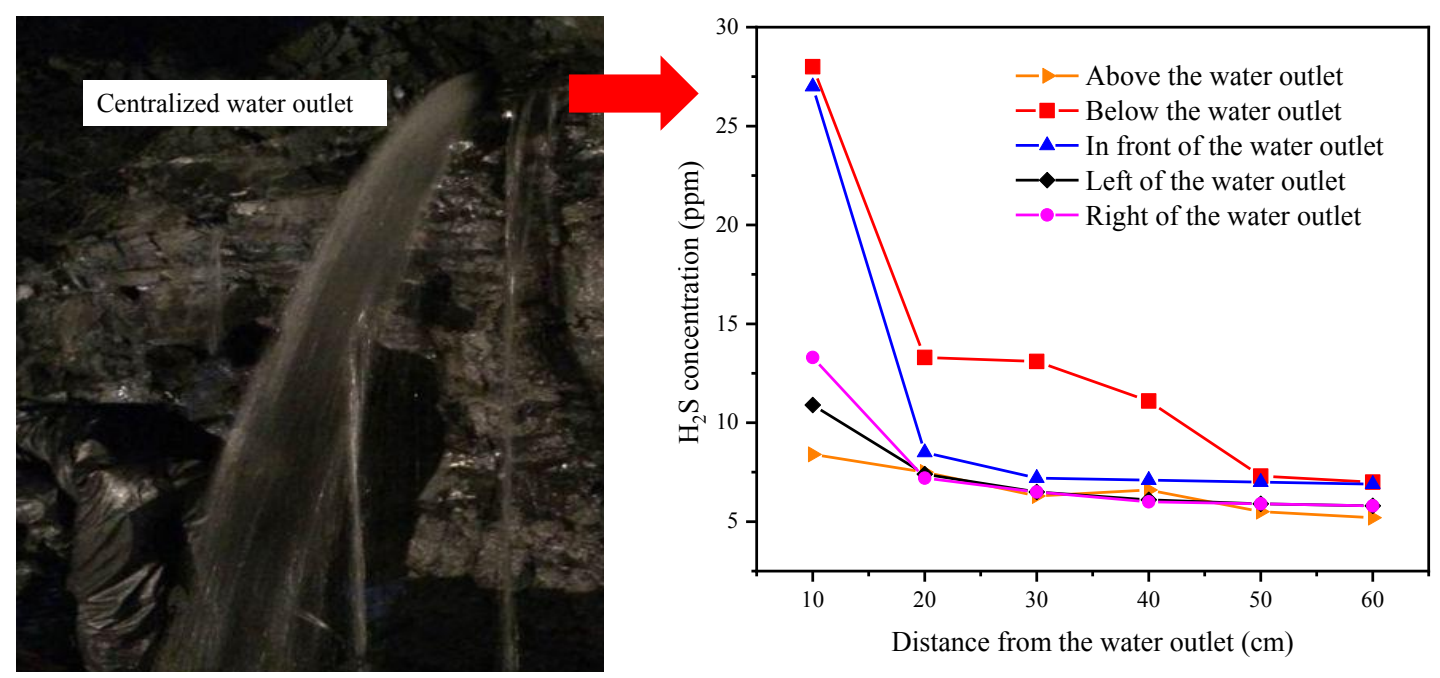

Fig. 6. Diffusion curve of $\mathrm{H}_{2} \mathrm{~S}$ concentration near the concentrated water outlet.

It needs to further study distribution characteristics of $\mathrm{H}_{2} \mathrm{~S}$ concentration from HD3K0+068 to HD3K0+178 of the 3\# transverse gallery under conditions, such as shotcreting as primary supports, grouting sealing and general ventilation. For this purpose, starting from $\mathrm{HD} 3 \mathrm{~K} 0+178$ in the excavating face, a group of $\mathrm{H}_{2} \mathrm{~S}$ concentrations was read along the left and right side walls of the tunnel at an interval of $30 \mathrm{~m}$ and a curve was drawn in Fig. 7. Data in the figure demonstrate that the $\mathrm{H}_{2} \mathrm{~S}$ concentration outwards the transverse gallery gradually rises, indicating that cumulative damage effects of dynamic disturbance induced by frequent blasting excavation on surrounding rock of the tunnel can aggravate harmful gas escape, such as $\mathrm{H}_{2} \mathrm{~S}$. A centralized water outlet is observed at location about $30 \mathrm{~m}$ from the tunnel face, where the $\mathrm{H}_{2} \mathrm{~S}$ concentration increases significantly, but it is much smaller than that without shotcreting as primary supports and grouting for water sealing. This implies that shotcreting as primary supports and grouting sealing can effectively reduce the amount of $\mathrm{H}_{2} \mathrm{~S}$ escaped. 


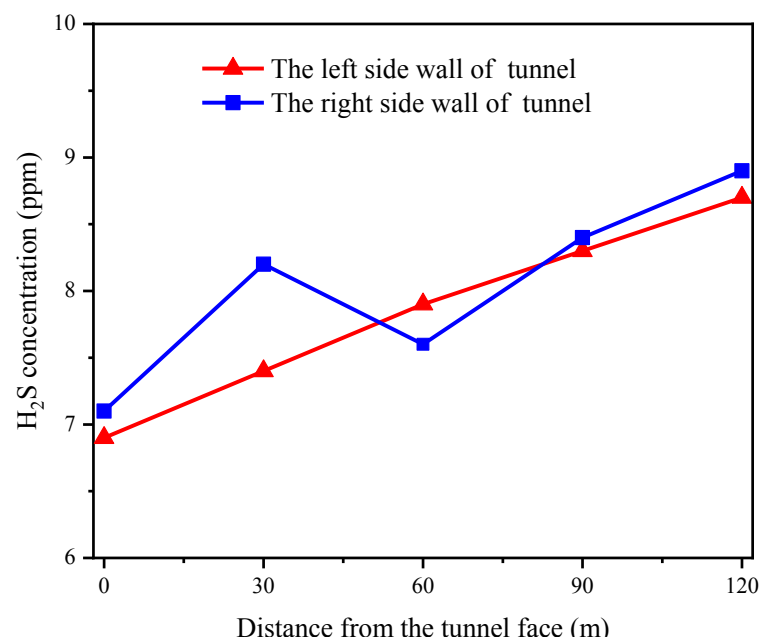

Fig. 7. $\mathrm{H}_{2} \mathrm{~S}$ concentration distribution curve after preliminary spraying concrete support.

\section{Analysis of harmful gas escape mechanism and influencing factors \\ Multi-field coupling numerical model and its validity verification}

(1) Coupling numerical model of stress, seepage and damage fields

COMSOL Multiphysics is a finite element numerical simulation software for multi-physics coupling based on the method of solving partial differential equations or equations.Based on COMSOL Multiphysics, mechanisms of harmful gas escape in the process of blasting excavation of the tunnel were simulated and analyzed. The following assumptions are made: the process of gas migration is isothermal and only single-phase gas is present in rock mass. The gas permeability is isotropic and gas whose viscosity coefficient is a constant is contained in rock mass. By simplifying the tunnel and cavity into circles, a three-dimensional model with dimensions of $100 \mathrm{~m} \times 100 \mathrm{~m} \times 100 \mathrm{~m}$ was built in Fig. 8. The diameters of the cavity and tunnel are $5 \mathrm{~m}$ and $5 \mathrm{~m}$, respectively and the net distance from the cavity to the tunnel is $15 \mathrm{~m}$.

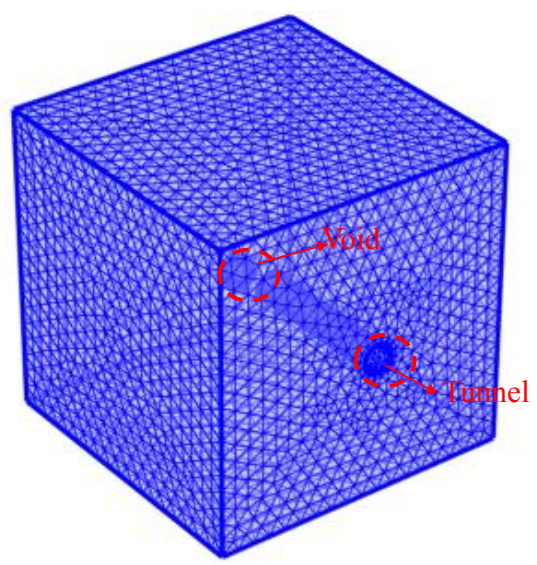

Fig. 8. Three-dimensional numerical model.

In-situ stress boundary conditions are applied at the top, front and left boundaries of the model, and roller support constraints are applied on the right, rear and bottom boundaries. At 
present, trigonometric function and double exponential function are mainly used for time history relation of load change in borehole. However, the determination of coefficient of double exponential function depends on field test data very much, which has great limitation and randomness in practical application (Lu et al. 2012). In this paper, Based on Hoek-Brown strength criterion, the function curve of triangle blasting load in Fig. 9 was selected for calculating blasting. The total duration of action is $17 \mathrm{~ms}$, including an ascending phase of 2.3 $\mathrm{ms}$ and a descending phase of $14.7 \mathrm{~ms}$, and the peak stress under blasting load is $50 \mathrm{MPa}(\mathrm{Lu}$ et al. 2012).

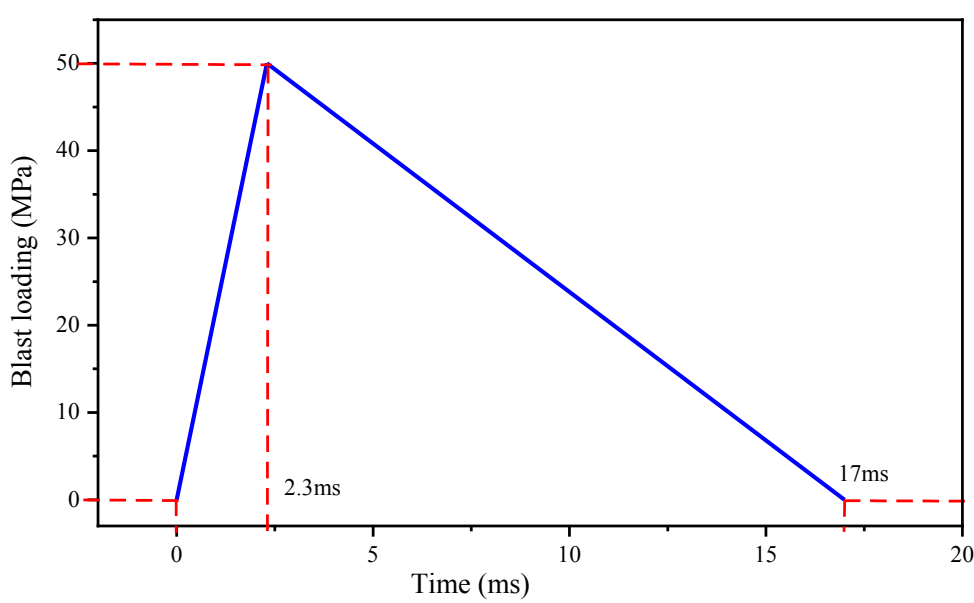

Fig. 9. Time-history curve of equivalent blast loading.

A laboratory test was carried out by sampling in the field. Based on this, the initial physical and mechanical parameters of surrounding rock mass of the tunnel with a gas-containing void and water-containing void were obtained, as listed in Table 1.

Table 1 Initial physical and mechanical parameters of cavity rock mass.

\begin{tabular}{ccccc}
\hline & Young's modulus (GPa) & Poisson's ratio & Density of rock $\left(\mathrm{km} / \mathrm{m}^{3}\right)$ & Porosity \\
Gas-containing & 50 & 0.21 & 2700 & 0.05 \\
void & Hydraulic conductivity & Fluid density & Compressibility of fluid & $\begin{array}{c}\text { Dynamic } \\
\text { viscosity }\end{array}$ \\
& $(\mathrm{m} / \mathrm{s})$ & $\left(\mathrm{km} / \mathrm{m}^{3}\right)$ & $1 \mathrm{e}-5$ & $1.84 \mathrm{e}-5$ \\
\hline \multirow{2}{*}{$\begin{array}{c}4.2 \mathrm{e}-11 \\
\text { Water-containing }\end{array}$} & 0.77 & Pensity of rock $\left(\mathrm{km} / \mathrm{m}^{3}\right)$ & Porosity \\
void & Hydraulic conductivity & Fluid density & Compressibility of fluid & Dynamic \\
& $(\mathrm{m} / \mathrm{s})$ & $\left(\mathrm{km} / \mathrm{m}^{3}\right)$ & viscosity
\end{tabular}

In analysis of the multi-field coupling model, the governing equation for the deformation field of rock mass is a mechanical equilibrium equation considering pore pressure, which is solved based on the built-in application mode of static plane strain of COMSOL MultiphysicsIn analysis of the multi-field coupling model, the governing equation for the deformation field of rock mass is a mechanical equilibrium equation considering pore 
pressure, which is solved based on the built-in application mode of static plane strain of COMSOL Multiphysics. The governing equation for the seepage field is a highly nonlinear equation, which is solved by the partial differential equation (PDE) (Qu et al. 2020). The module of Darcy's law is selected as seepage conditions and there are no flow boundaries around it. An appropriate cavity pressure is selected according to the occurrence state. When simulating the influence of the excavation of a gas-containing void, the seepage conditions are removed, and only the stress field and damage field are analyzed.

(2) Validation of numerical model

Under in-situ stress of $50 \mathrm{MPa}$, Fig. 10 shows the distribution of Darcy velocity of surrounding rock around the tunnel face and the water-containing void in the tunnel under the combined action of in-situ stress and blasting load. It can be observed from the figure that Darcy velocity is larger in the area with a close distance between the tunnel and the water-containing void and is distributed symmetrically along the connecting line between centers of circles of the tunnel and the water-containing void. Darcy velocity is redistributed under dynamic disturbance.

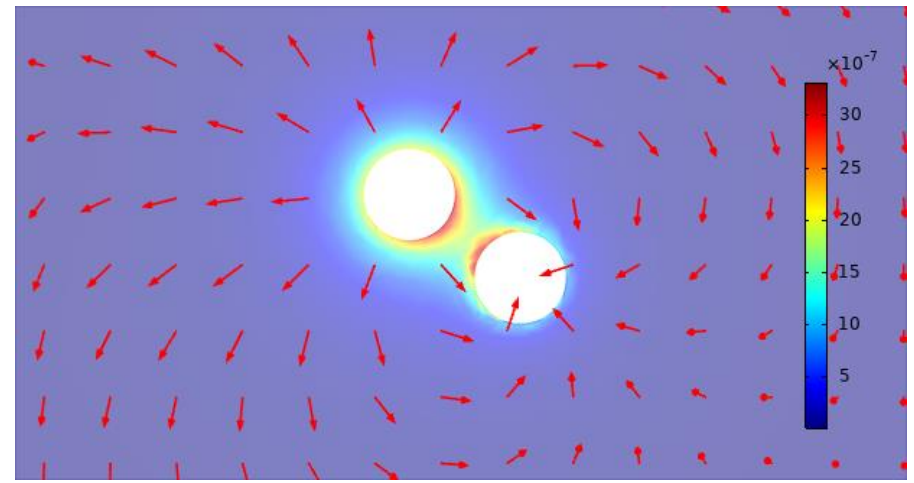

Fig. 10. Darcy velocity of the surrounding rock.

Under in-situ stress of $50 \mathrm{MPa}$, damage distribution on three sections of surrounding rock of the tunnel under the combined action of in-situ stress and blasting load is shown in Fig. 11. It can be seen from the figure that under the coupled action of in-situ stress, seepage and blasting load, the damage degree and extent of surrounding rock on the left side of the tunnel are the largest, followed by the right side, while those at the top are the smallest.

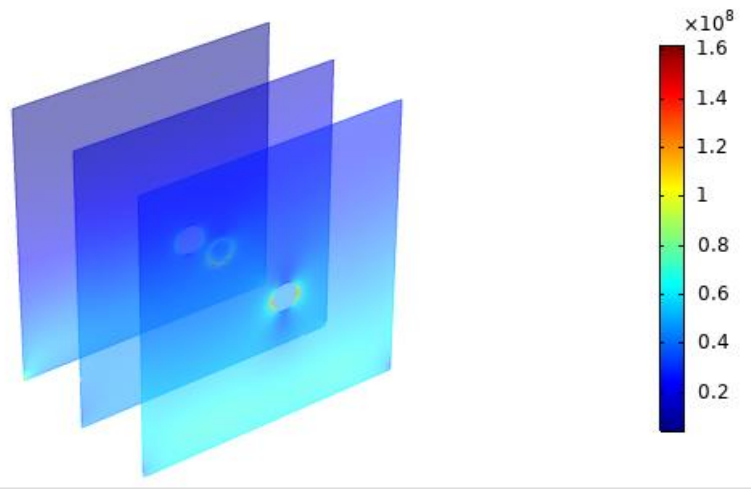

Fig. 11. Damage distribution of surrounding rock in tunnel. 
Based on numerical simulation and field measurement, the average damage depth of rock mass is obtained, as demonstrated in Fig. 12 and damage extents on vault, floor and both side walls are different. Due to cumulative damage effects of multiple repeated blasting on surrounding rock in practical engineering, the damage extent in the field test is larger than that in numerical calculation. Excluding this difference, the field measurement results are in good agreement with the numerical calculation results, which further verifies the correctness of the 266 model calculation.

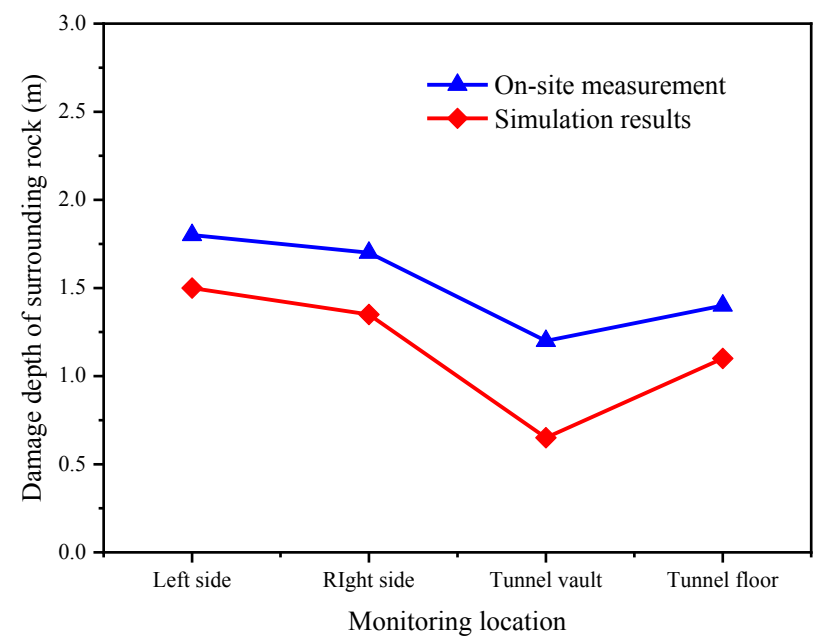

Fig. 12. Comparison of on-site measurement and simulation results.

\section{Escape mechanism of harmful gas under blasting load}

270

(1) Effect of the blasting load on the seepage and damage field in surrounding rock of the 271 tunnel with the water-containing void

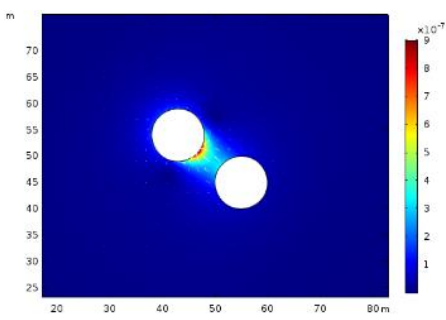

(a) blast loading $=0 \mathrm{MPa}$

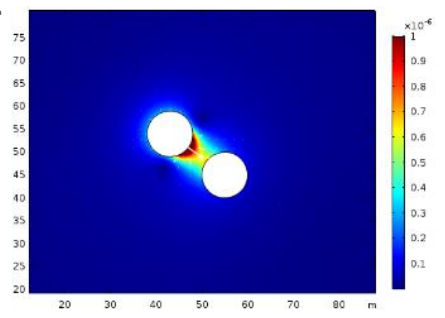

(b) blast loading $=25 \mathrm{MPa}$

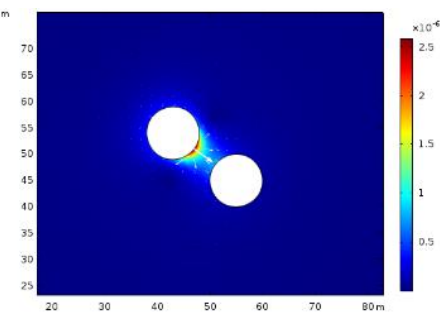

(c) blast loading $=50 \mathrm{MPa}$

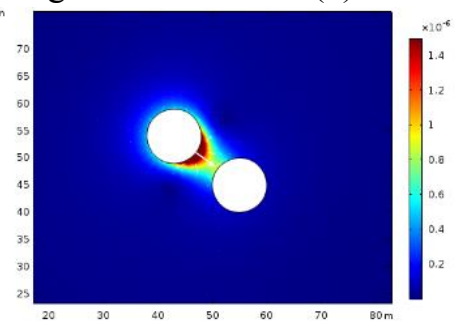

(d) blast loading $=75 \mathrm{MPa}$

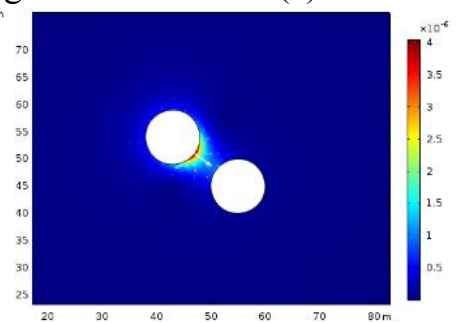

(e) blast loading $=10 \mathrm{MPa}$

Fig. 13. Darcy velocity distribution of tunnel under different blast loads

Under the combined action of blasting load and in-situ stress, Fig. 13 shows changes of Darcy velocity around the tunnel and the water-containing void with the blasting load. When the blasting load is $0 \mathrm{MPa}$, peak Darcy velocity is the minimum, which is concentrated near 
the water-containing void, and points to the void. With the increase of the blasting load, the peak Darcy velocity around the tunnel and the water-containing void rises. Furthermore, Darcy velocity around the water-containing void increases more obviously and it points to the tunnel.

Figure 14 illustrates distribution of damages of different blasting loads to surrounding rock under in-situ stress. As the blasting load is $0 \mathrm{MPa}$, the damage degree changes slightly and the damage zone is concentrated in the vicinity of the connecting line between centers of circles of the void and the tunnel. With the rise of the blasting load, the damage zone is concentrated in the zone outside of the connecting line, showing obvious changes in location. The damage degree of surrounding rock of the tunnel is positively correlated with the blasting load and changes the permeability coefficient of surrounding rock, thus affecting the water inflow into the tunnel.

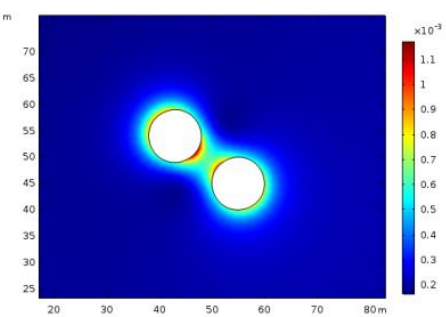

(a) blast loading $=0 \mathrm{MPa}$

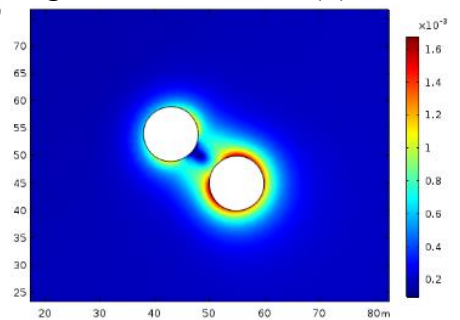

(d) blast loading $=75 \mathrm{MPa}$

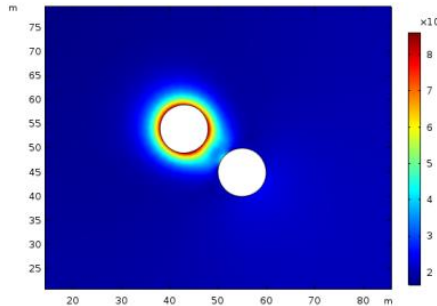

(b) blast loading $=25 \mathrm{MPa}$

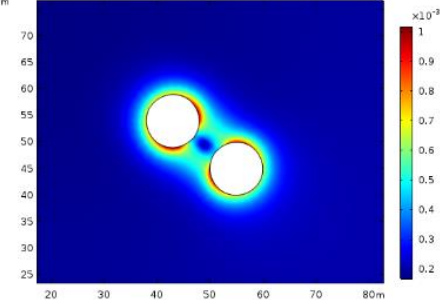

(c) blast loading $=50 \mathrm{MPa}$

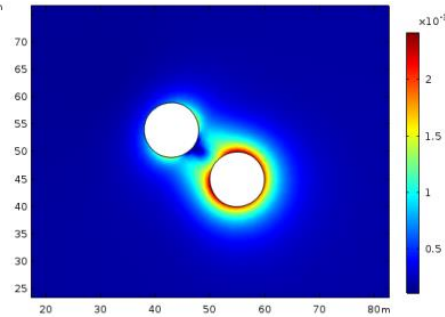

(e) blast loading $=10 \mathrm{MPa}$

Fig. 14. Damage distribution of tunnel surrounding rock under different blast loads.

Figure 15 illustrates the water inflow into the tunnel under different blasting loads under in-situ stress. By fitting, the curve for the relationship between the water inflow into the tunnel and the blasting load was obtained. It can be observed from the figure that when in-situ stress and parameters of the water-containing void remain unchanged, with the increase of the blasting load, the water inflow exponentially rises, while the increase rate gradually reduces. When the blasting load increases from 0 to $100 \mathrm{MPa}$, the water inflow rises by about $3.8 \mathrm{~m}^{3} / \mathrm{d}$. After the blasting load exceeds $25 \mathrm{MPa}$, the water inflow is almost no longer affected by the blasting load. The reason why water is able to dissolve gas is that there are cavities between water molecules in water phases. When gas enters the cavities, it will release the heat of dissolution. When the kinetic energy of gas molecules dissolved in the cavities in water phases is enough to overcome van der Waals potential energy, gas will turn back to the gas phase. Relevant studies reveal that the solubility of $\mathrm{H}_{2} \mathrm{~S}$ in water is related to factors, like temperature and pressure (Roberto et al. 2008; Vorholz et al. 2008). In the meanwhile, sulfide in water is mainly produced 
by decomposition of sulfur-containing organic matters and reduction of sulfate by bacteria in the presence of ozone, and the latter plays the dominated role. Finally, $\mathrm{H}_{2} \mathrm{~S}$ gas escapes from water and is dispersed in the air.

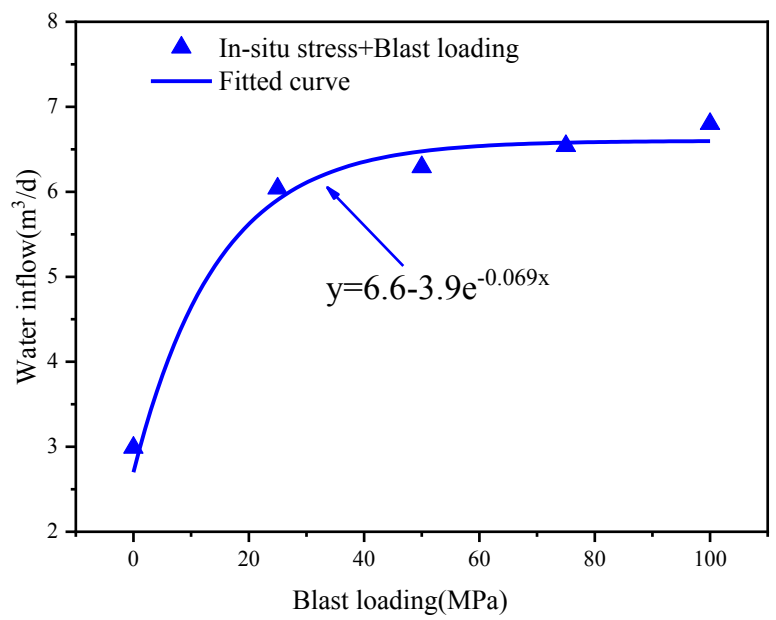

Fig. 15. Influence of blast loading on water inflow in tunnel.

(2) Effect of the blasting load on the damage field in surrounding rock of the tunnel with the gas-containing void

Figure 16 displays distribution of damages of different blasting loads to surrounding rock of the tunnel under in-situ stress. When the blasting load is $0 \mathrm{MPa}$, the damage degree changes slightly and a damage zone is concentrated near the connecting line between centers of circles of the gas-containing void and the tunnel. With the increase of the blasting load, the damage zone is concentrated in the zone outside this connecting line, showing an obvious change in location. The damage degree of the tunnel is positively correlated with the blasting load and changes the permeability coefficient of surrounding rock around the tunnel, thus influencing the gas inflow into the tunnel.

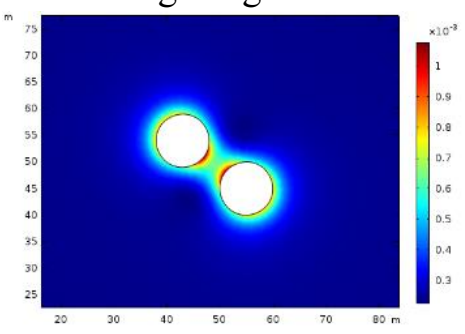

(a) blast loading $=0 \mathrm{MPa}$

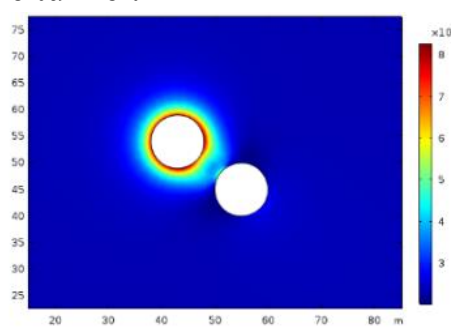

(b) blast loading $=25 \mathrm{MPa}$

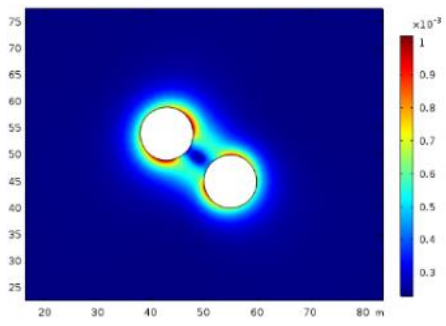

(c) blast loading $=50 \mathrm{MPa}$

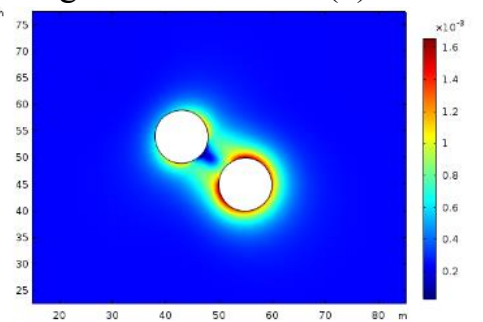

(d) blast loading $=75 \mathrm{MPa}$

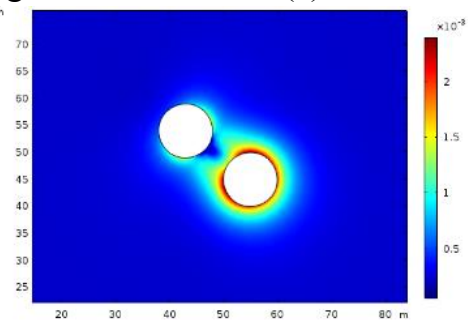

(e) blast loading $=10 \mathrm{MPa}$

Fig. 16. Damage distribution of tunnel surrounding rock under different blast loads. 
Figure 17 demonstrates the gas inflow into the tunnel under different blasting loads under in-situ stress. Through fitting, the curve for the relationship between the gas inflow into the tunnel from the gas-containing void and the blasting load was obtained. It can be seen 321 from the figure that when the in-situ stress and parameters of the gas-containing void are constant, the gas inflow into the tunnel from the gas-containing void exponentially increases with the blasting load and the increase rate gradually decreases. As the blasting load rises from 0 to $100 \mathrm{MPa}$, the gas inflow increases by $7.02 \mathrm{~m}^{3} / \mathrm{d}$, at the increase rate of $21.6 \%$.

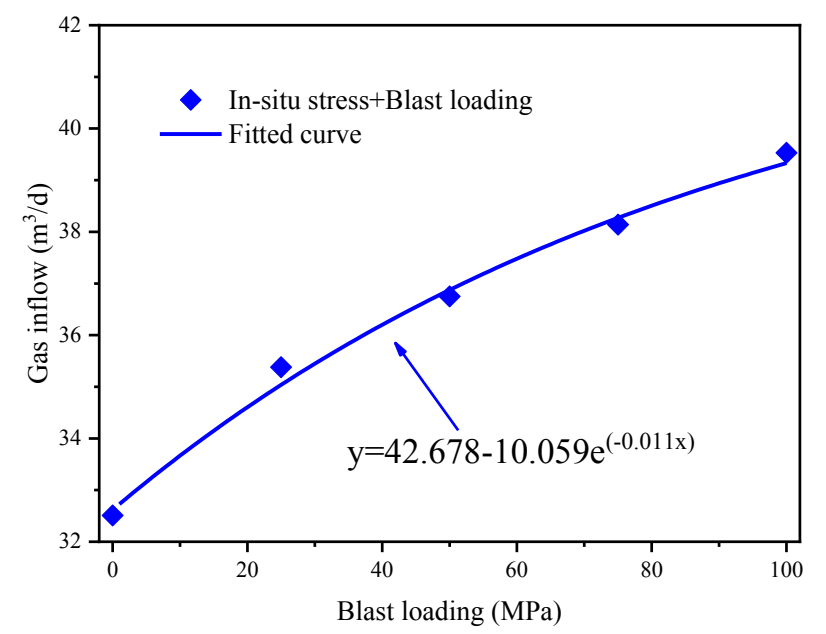

Fig. 17. Influence of blast loading on gas inflow in tunnel.

\section{Analysis of influencing factors of water-soluble gas escape}

(1) Impact of properties of surrounding rock on the water inflow into the tunnel

Under two working conditions, namely the action of in-situ stress alone and combined action of in-situ stress and blasting load, effects of changes of factors, such as horizontal in-situ stress, coefficient of lateral pressure and net distance between the water-containing void and the tunnel on the water inflow were analyzed. By fitting numerical calculation results, the curves for the water inflow into the tunnel under different factors were obtained, as displayed in Fig. 18.

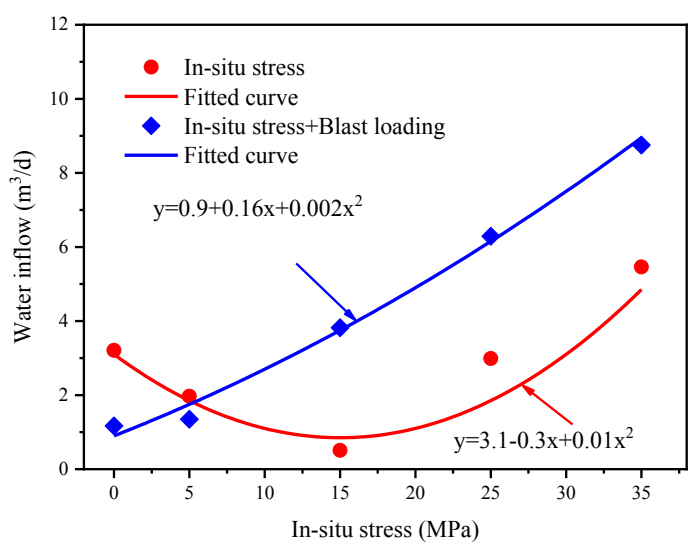

(a) Horizontal in-situ stress variation.

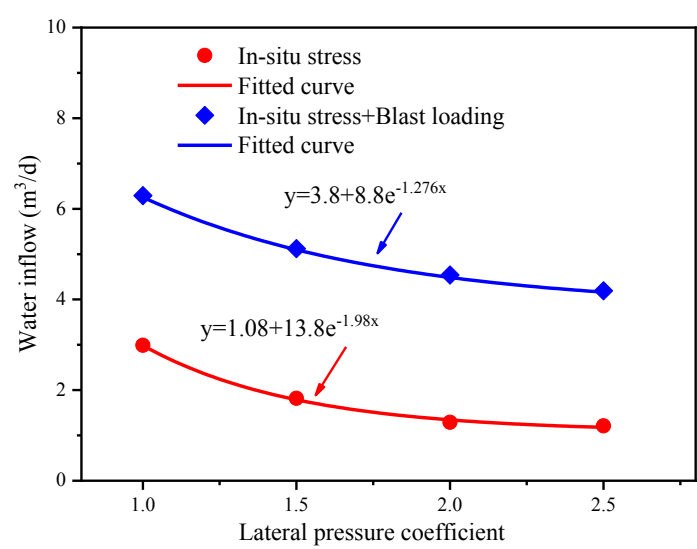

(b) Lateral pressure coefficient variation. 


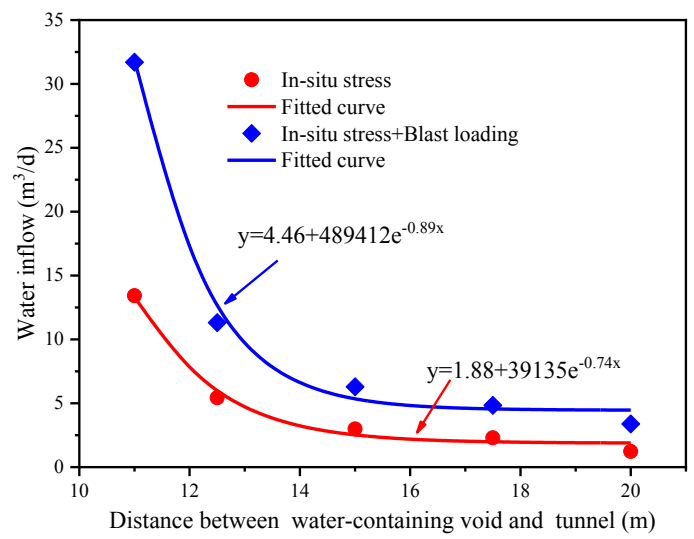

(c) Distance variation between water-containing void and tunnel.

Fig. 18. Influence of surrounding rock characteristics on water inflow in tunnel.

As shown in Fig. 18(a), when the in-situ stress acts alone, with the increase of the horizontal in-situ stress, the water inflow into the tunnel firstly reduces and then rises. The reason for such a phenomenon is that when the in-situ stress is small, the in-situ stress is partially offset by the pressure in the void, so the water inflow into the tunnel firstly decreases. Under the combined action of blasting load and in-situ stress, the water inflow into the tunnel gradually rises with the increase of the horizontal in-situ stress, with a small increase rate in the early stage. As demonstrated in Fig. 18(b), the water inflow into the tunnel exponentially decreases with the coefficient of lateral pressure under both of the two working conditions and the decrease rate also gradually reduces. Relatively speaking, the coefficient of lateral pressure has a small influence on the water inflow into the tunnel. As displayed in Fig. 18(c), with the increase of the net distance between the water-containing void and the tunnel, the gas inflow exponentially reduces. After the net distance rises to $15 \mathrm{~m}$, the water inflow basically keeps unchanged.

(2) Effect of parameters of the water-containing void on the water inflow into the tunnel

Under the two working conditions, namely the action of in-situ stress alone and combined action of in-situ stress and blasting load, the effects of the diameter of the water-containing void and the pressure in the void on the water inflow into the tunnel were analyzed. On this basis, the curves of the water inflow into the tunnel under different factors were obtained, as shown in Fig. 19.

As shown in Fig. 19(a), under the two different working conditions, the diameter of the gas-containing void exerts the basically consistent influence laws on the water inflow into the tunnel. With the increase of the diameter of the gas-containing void, gas inflow exponentially rises and the increase rate also gradually rises. It can be seen from Fig. 19(b) that under the in-situ stress alone, as the pressure in the void increases, the water inflow into the tunnel decreases. When the pressure in the void rises to $12 \mathrm{MPa}$, the water inflow into the tunnel reduces to the lowest and then gradually rises with the pressure in the void. Under the combined action of blasting load and in-situ stress, with the increase of the pressure in the 
void, the water inflow into the tunnel decreases. When the pressure in the void rises to 15 $\mathrm{MPa}$, the water inflow into the tunnel decreases to the lowest and then gradually increases with the pressure.

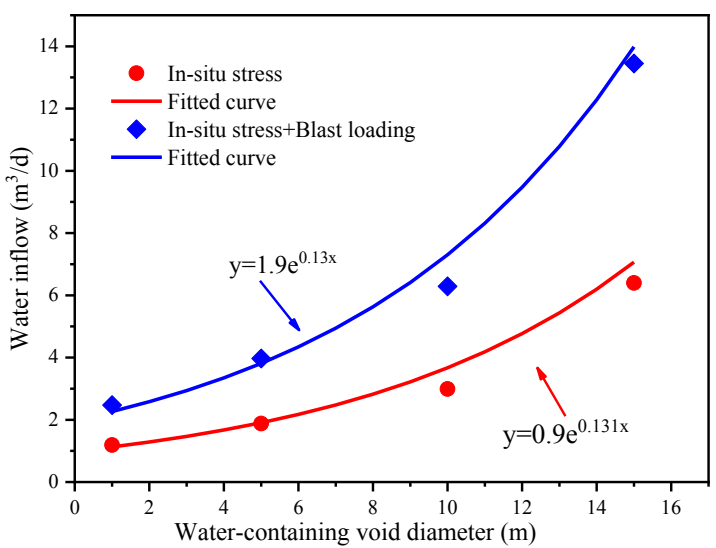

(a) Water-containing void diameter variation.

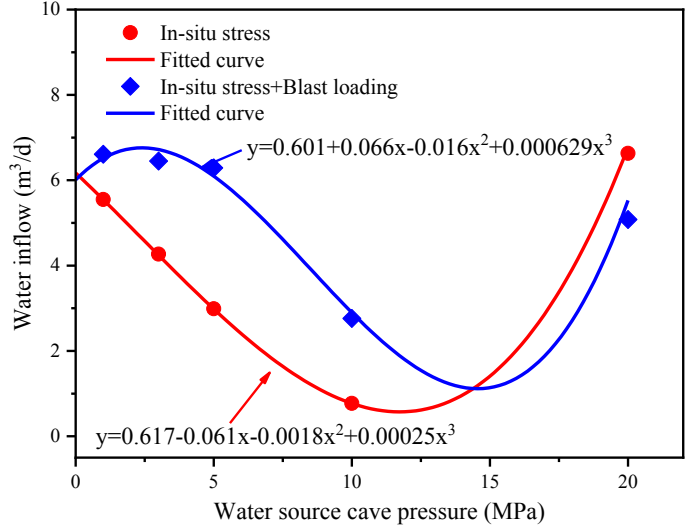

(b) Water-containing void pressure variation.

Fig. 19. Influence of water source cave parameters on tunnel water inflow.

\section{Analysis of influencing factors of insoluble gas escape}

(1) Impact of properties of surrounding rock on the gas inflow into the tunnel

By considering two different working conditions, namely the action of in-situ stress alone and the combined action of in-situ stress and blasting load, the effects of changes of factors, such as horizontal in-situ stress, coefficient of lateral pressure and net distance between the gas-containing void and the tunnel on the gas inflow into the tunnel were analyzed. By fitting numerical calculation results, the curves of the gas inflow into the tunnel under different factors were obtained, as shown in Fig. 20.

It can be observed from Fig. 20 that the action of in-situ stress alone and combined action of in-situ stress and blasting load do not change the shape of the curves for the relationship between the amount of escaped gas and various factors. However, more significant influence laws are shown under the combined action. Fig. 20(a) demonstrates that the gas emission from the gas-containing void linearly rises with the horizontal in-situ stress at the same increase rate under the two working conditions. Fig. 20(b) illustrates that the gas emission from the gas-containing void exponentially decreases with the coefficient of lateral pressure under the two working conditions and the exponential coefficient of the function does not change. As shown in Fig. 20(c), with the increase of the net distance between the gas-containing void and the tunnel, the gas emission from the gas-containing void exponentially reduces under the two working conditions. After the net distance reaches $15 \mathrm{~m}$, the gas emission basically remains unchanged. 


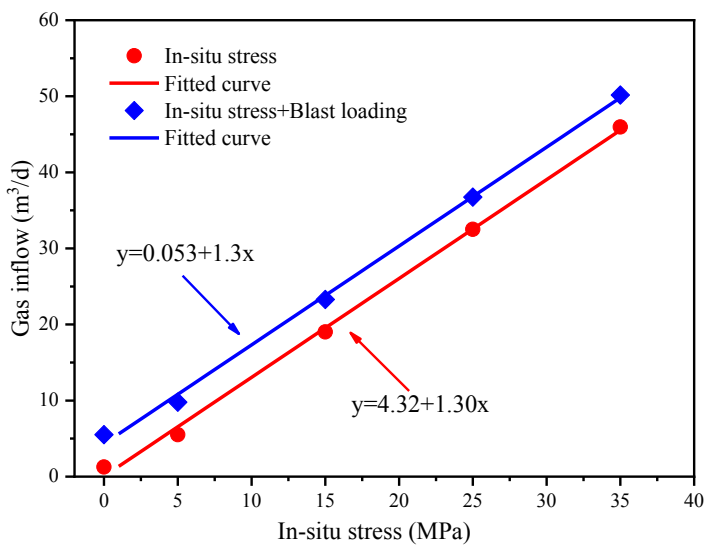

(a) Horizontal crustal stress variation.

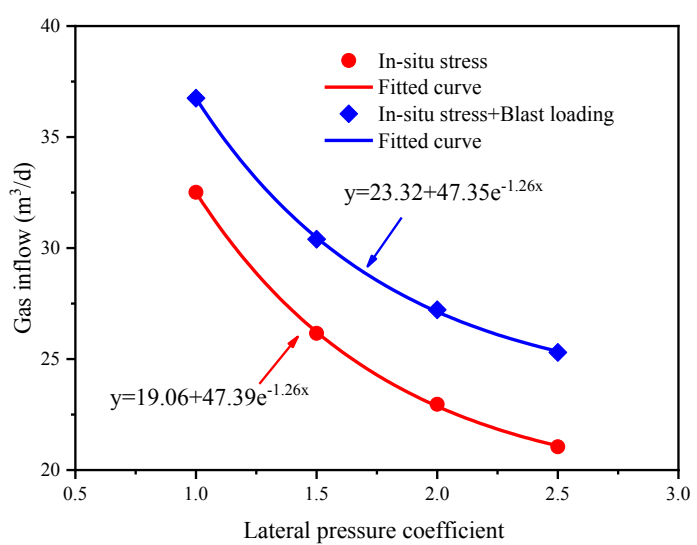

(b) Lateral pressure coefficient variation.

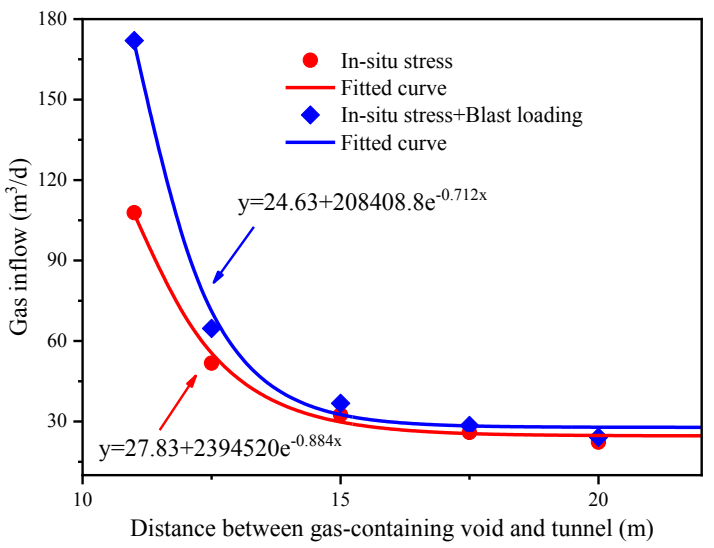

(c) Distance variation between gas-containing void and tunnel.

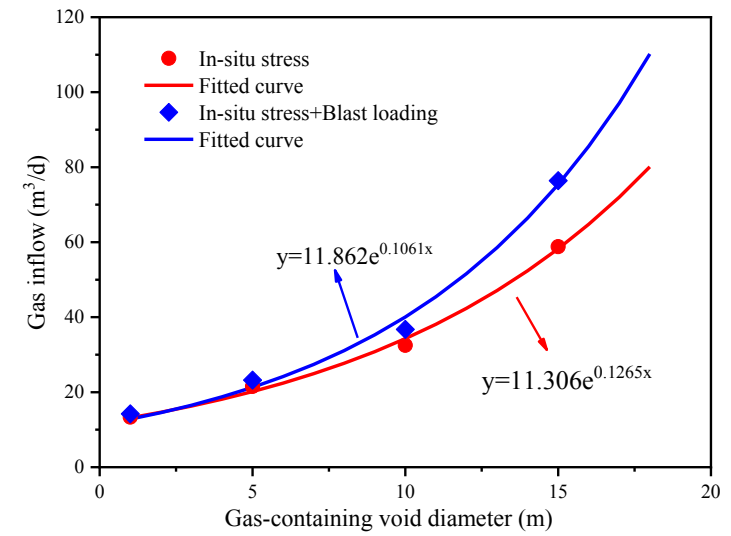

(a) Gas-containing void diameter variation.

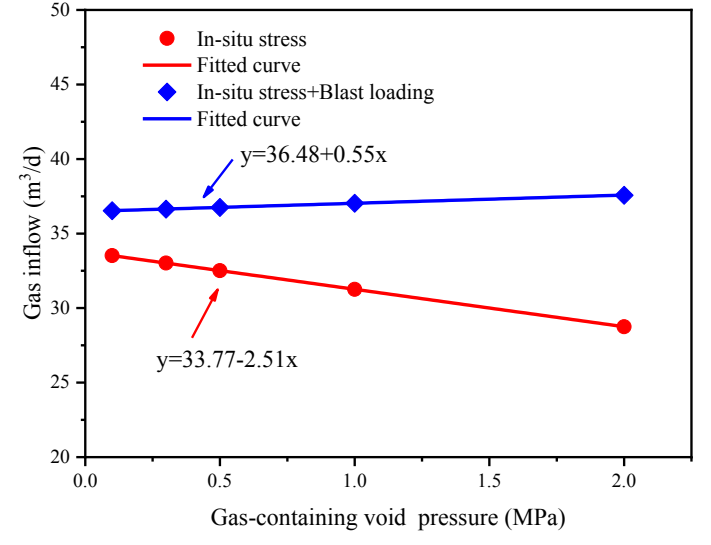

(b) Gas-containing void pressure variation.

Fig. 21. Influence of gas-containing void parameters on tunnel gas inflow. 
As displayed in Fig. 21(a), under the two working conditions, the diameter of the

395

396

397

398

399

400

401

402

403

404

405

406

407

408

409

410

411

412

413

414

415

416

417

418

419

420

421

422

423

424

425

426

427

428

429

430

gas-containing void has the consistent influence laws on the amount of escaped gas, namely the amount of escaped gas exponentially rises with the diameter, and the increase rate gradually rises. The reason for such a phenomenon is that with the increase of the diameter of the void, its edge is closer to the position of blasting excavation of the tunnel, while the explosion-induced stress wave attenuates very significantly in the early stage, so the influence is greater. It can be observed from Fig. 21(b) that with the increase of the pressure in the gas-containing void, the gas inflow linearly changes with a small amplitude. However, under the two working conditions, the influence trends are contrary. Under the action of in-situ stress alone, the gas inflow into the tunnel decreases with the increase of the pressure in the gas-containing void; on the contrary, the gas inflow into the tunnel rises with the increase of the pressure in the void under the combined action of blasting load and in-situ stress.

\section{Conclusions}

In this paper, based on real-time monitoring data of harmful gases during blasting and excavation of Yuelongmen Tunnel on Chengdu-Lanzhou Railway, this study summarized laws and distribution characteristics of harmful gas escape intensified by the blasting excavation. By taking the water-containing void and gas-containing void as carriers, considering the influence of different in-situ stress, explosion load and void parameters, to carry out research on the escape mechanism of water-soluble $\left(\mathrm{H}_{2} \mathrm{~S}\right)$ and insoluble $\left(\mathrm{CH}_{4}\right)$ toxic and harmful gases under the coupling effect of stress-seepage-damage. The conclusions are made as follows:

(1) The amount of escaped harmful gases, such as methane and $\mathrm{H}_{2} \mathrm{~S}$ is closely correlated with lithology of surrounding rock, occurrence conditions of the deep rock mass, development degree of structural factures and void parameters. The damage of surrounding rock caused by dynamic disturbance during blasting excavation is the main reason of aggravating harmful gas and groundwater escape. $\mathrm{H}_{2} \mathrm{~S}$ dissolved in water can turn back to the gas phase and be dispersed in the air when the atmospheric pressure changes. Methods such as fine blasting to control surrounding rock damage and to drain the gas-liquid mixture in the cave in advance can effectively reduce the risk of harmful gases during tunnel construction.

(2) The water inflow and gas inflow into the tunnel both exponentially increase with the blasting load. The gas inflow into the tunnel from the gas-containing void constantly, slowly rises with the increase of the blasting load. Owing to the tunnel with the water-containing void in the surrounding rock is subjected to the multi-field coupled action of stress, seepage and damage fields, the change trend is different. After the blasting load exceeds $25 \mathrm{MPa}$, the water inflow in the tunnel with the water-containing void in the surrounding rock is basically not affected by the increase of the blasting load.

(3) When the diameters of the water-containing void and gas-containing void increase, the gas inflow and water inflow into the tunnel both exponentially rise. The net distance of 15 
$\mathrm{m}$ from the water-containing void and gas-containing void to the tunnel is considered as the critical distance of influence. The coefficient of lateral pressure has basically same influence laws on the water inflow and gas inflow into the tunnel. The gas inflow into the tunnel linearly changes with the pressure in the gas-containing void, but the overall change is slight. With the increasing pressure in the water-containing void, the water inflow into the tunnel firstly reduces and then rises.

\section{Acknowledgments}

This work was supported by the National Natural Science Foundation of China (Grant No. 51979208), the Natural Science Foundation of Hainan Province (Grant No. 420QN291), and the Sanya Yazhou Bay Science and Technology City Administration Scientific research project (No. SKJC-KJ-2019KY02). The authors would like to thank the editors and reviewer for their careful review of this paper.

\section{Reference}

Abdollahisharif J, Bakhtavar E, Nourizadeh H (2016) Green biocompatible approach to reduce the toxic gases and dust caused by the blasting in surface mining. Environ Earth Sci 75:191. https://doi.org/10.1007/s12665-015-4947-9.

Chang XK, Chai JR, Luo JP, Qin Y, Xu ZG, Cao J (2020) Tunnel ventilation during construction and diffusion of hazardous gases studied by numerical simulations. Build Environ 177:106902. https://doi.org/10.1016/j.buildenv.2020.106902.

Cong HY, Bi MS, Bi YB, Li YC, Jiang HP, Gao W (2021) Experimental studies on the smoke extraction and smoke control performance by the ventilation shaft in extra-long road tunnels. Int J Therm Sci 160:106677. https://doi.org/10.1016/j.ijthermalsci.2020.106677.

Creedy DP (1988) Geological controls on the formation and distribution of gas in British coal measure strata. Int J Coal Geol 10:1-31. https://doi.org/10.1016/0166-5162(88)90002-X.

Esworth D, Goodman RE (1986) Characterization of rock fissure hydraulic conductivity using idealized wall roughness profiles. Int $J$ Rock Mech Min Sci 23:233-243. https://doi.org/10.1016/0148-9062(86)90969-1.

Gao K, Liu ZM, Jia JZ, Liu ZY, Aiyiti Y, Qi ZP, Wu YJ, Li SN (2020) Study on Flame Spread Characteristics of Flame-Retardant Cables in Mine. Adv Polym Tech 2020:1-7. https://doi.org/10.1155/2020/8765679.

Hong KR (2017) Typical Underwater Tunnels in the Mainland of China and Related Tunneling Technologies. Engineering 3:871-879. https://doi.org/10. 1016/j.eng.2017.12.007.

Huang CG, Zhang YB, He JH, Luo YJ, Sun ZG (2019) Permeability improvements of an outburstprone coal seam by means of presplitting and blasting with multiple deep boreholes. Energy Sci Eng 7:2223-2236. https://doi.org/ 10.1002/ese3.426. 
Kang DY, Luo HF, (2008) Research on anti-corrosive air impermeable concrete and its application in Lishuwan tunnel project. Chin J Undergr Space and Eng, 05, 949-952.

Kurnia JC, Agus PS, Arun SM (2014) CFD simulation of methane dispersion and innovative methane management in underground mining faces. Appl Math Model 38:3467-3484. https://doi.org/10.1016/j.apm.2013.11.067.

Lin BQ, Yan FZ, Zhu CJ, Zhou Y, Zou Q, Guo C, Liu T (2015) Cross-borehole hydraulic slotting technique for preventing and controlling coal and gas outbursts during coal roadway excavation. J Nat Gas Sci Eng 26:518-525. https://doi.org/ 10.1016/j.jngse.2015.06.035.

Lu WB, Yang JH, Yan P, Chen M, Zhou CB, Luo Y, Jin L (2012) Dynamic response of rock mass induced by the transient release of in-situ stress. Int J Rock Mech Min 53:129-141. https://doi.org/10.1016/j.ijrmms.2012.05.001.

Lugin IV, Alferova EL (2019) Integrated performance analysis of ventilation schemes for double-line subway tunnel.OP Conf Ser Earth Environ Sci 262:012043. https://doi.org/10.1088/1755-1315/ 262/1/012043.

Marcia LH, Richard JM (2007) Monitoring and removal of CO in blasting operations. Saf Sci 46:1393-1405. https://doi.org/10.1016/j.ssci.2007.10.003.

Naveen P, Asif M, Ojha K (2018) Integrated fractal description of nanopore structure and its effect on $\mathrm{CH}_{4}$ adsorption on Jharia coals. Fuel 232:190-204. https://doi.org/10.1016 /j.fuel.2018.05.124.

Olga A, Maite P, Helena GB, Carles MB, Oriol G (2015) Implications of downstream nitrate dosage in anaerobic sewers to control sulfide and methane emissions. Water Res 68:522-532. https://www.sci-hub.ren/10.101 6/j.watres.201.

Pan RK, Cheng YP, Yuan L, Yu MG, Dong J (2014) Effect of bedding structural diversity of coal on permeability evolution and gas disasters control with coal mining. Nat Hazards 73:531-546. https://doi.org/10.1007/s11069-014-1086-7.

Qu DX, Luo Y, Li XP, Wang G, Zhang G, Xu K (2020) Study on the stability of rock slope under the coupling of stress field, seepage field, temperature field and chemical field. Arab J Sci Eng 45:1-15. https://doi.org/10.1007/s13369-020-04723-z.

Paoin K, Ueda K, Ingviya T, Buya S, Phosri A, Seposo XT, Seubsman SA, Kelly M, Sleigh A, Honda A, Takano H (2020) Long-term air pollution exposure and self-reported morbidity: A longitudinal analysis from the Thai cohort study (TCS). Environ Res 110330. https://doi.org/10.1016/j.envres.2020.110330.

Roberto LR., Jose', A., 2008. Molecular Dynamics Simulations of the Solubility of $\mathrm{H}_{2} \mathrm{~S}$ and $\mathrm{CO}_{2}$ in Water. J Mex Chem Soc, 52(1), 88-92.

Shao JF, Rudnicki JW (2000) A microcrack-based continuous damage model for brittle geomaterials. Mech Mater 32:607-619. https://doi.org/10.1016/S0167-6636(00)00024-7.

Shepherd J, Rixon LK, Griffiths L (1981) Outbursts and geological structures in coal mines: A review. Int J Rock Mech Min 18:267-283. https://doi.org/10.1016/0148-9062(81)91192-X. 
Tang CA, Tham LG, Lee PKK, Yang THL, Li C (2002) Coupled analysis of flow, stress and damage (FSD) in rock failure. Int J Rock Mch Min 39:477-489. https://doi.org/1 0.1016/S1365-1609(02)00023-0.

Vorholz J, Maurer G (2008) Molecular simulation of the salting out effect in the system $\mathrm{H}_{2} \mathrm{~S}-\mathrm{H}_{2} \mathrm{O}-\mathrm{NaCl}$. Phys Chem Chem Phys 10:7247-56. https://doi.org/10.1039/b810728a.

Wang CJ, Yang SQ, Li XW (2018) Simulation of the hazard arising from the coupling of gas explosions and spontaneously combustible coal due to the gas drainage of a gob. Process Saf Environ 118:296-306. https://doi.org/10.1016/j.psep.2018.06.028.

Wang, XF (2013) Experimental study on air tightness of concrete used in high gas tunnel. J Railway Eng Soc 30:75-81.

Xie ZC, Zhang DM, Song ZL, Li MH, Liu C, Sun DL (2017) Optimization of drilling layouts based on controlled presplitting blasting through strata for gas drainage in coal roadway strips. Energies 10:1228. https://doi.org/10.3390/en10081228.

Xu JZ, Zhai C, Qin L (2017) Mechanism and application of pulse hydraulic fracturing in improving drainage of coalbed methane. J Nat Gas Sci Eng 40:79-90. https://doi.org/10.1016/j.jngse.2017. 02.012

Yan QS, Zhang YN, Sun QW (2020) Characteristic study on gas blast loadings in an urban utility tunnel. J Perform Constr Fac 34:04020076. https://doi.org/10.1061/(ASCE)CF.1943 -5509.0001477 .

Yan QX, Yang K, Wu W, He FS (2020) Prevention and control of gas hazards in a tunnel under construction: a case study. Environ Earth Sci 79:253-266. https://doi.org/10.1007/s 12665-020-09065-5.

Yang D, Dong S, He M, Zhang ZJ, Du T, Ji WH (2020) Experimental study on the performance of hybrid ventilation system combining forced longitudinal flow and shaft natural ventilation in tunnels. Tunn Undergr Space Technol 103:103491. https://doi.org/10.1016/j.tust.2020.103491.

Zhang C, Lin BQ, Zhou Y, Zhai C, Zhu CJ (2013) Study on "fracturing-sealing" integration technology based on high-energy gas fracturing in single seam with high gas and low air permeability. Int J Min Sci Techno 23:841-846. https://doi.org/10.1016/j.ijmst.2013.10.010.

Zhang GH, Chen W, Jiao YY, Wang H, Wang CT (2020) A failure probability evaluation method for collapse of drill-and-blast tunnels based on multistate fuzzy Bayesian network. Eng Geol 276:105752. https://doi.org/10.1016/j.enggeo.2020.105752. 